\title{
Toxicity assessment of natural and chemical coagulants using brine shrimp (Artemia salina) bioassay
}

\author{
G.V. AWOLOLA ${ }^{1}$, O. O. OLUWANIYI ${ }^{1}$, A. SOLANKE ${ }^{1}$, O.O. DOSUMU ${ }^{1 *}$ and \\ A. O. SHUIAB ${ }^{2}$ \\ ${ }^{1}$ Department of Chemistry, University of Ilorin, Ilorin, Nigeria. \\ ${ }^{2}$ Chemistry Programme, Abubakar Tafawa Balewa University, Bauchi, Nigeria. \\ *Corresponding author, E-mail: oltados@yahoo.com
}

\begin{abstract}
The brine shrimp lethality assay is considered a useful tool for preliminary assessment of toxicity. Food items and materials are essentially important to be screened (regularly) for toxicity. Coagulants used in preparing soft cheese or 'Wara' or 'Tofu', and in portable water treatment needed to be assessed preliminarily for toxicity and a simple bench top bioassay, brine shrimp lethality assay, is suitable for such preliminary investigation. Thirteen extracts obtained from seven coagulants, comprising five plants (natural) and two chemical coagulants used in this study showed different toxicity to brine shrimps. Aqueous extract of Terminalia cattapa displayed the highest toxicity $(0.1 \mu \mathrm{g} / \mathrm{ml})$, while the aqueous extract of Carica papaya was the least toxic of the plant extracts. $\mathrm{MgCl}_{2}$ was the least toxic of the two chemical coagulants. At high concentrations all the coagulants were toxic to brine shrimps but toxicity reduced as concentration decreased.

(c) 2010 International Formulae Group. All rights reserved.
\end{abstract}

Keywords: Calotropis procera, Carica papaya, Terminalia cattapa, Citrus lemon, coagulants, Artemia salina, lethality.

\section{INTRODUCTION}

An important and cheap source of protein for West African populace is cheese, locally called 'wara' or 'wara nkasi' in Nigeria. It is obtained by coagulating pasteurized milk. The milk is brought to coagulation at a specific temperature, $\mathrm{pH}$ and processing time with an appropriate coagulant. The coagulated milk is poured into a small basket or strainer in order to drain and to give the cheese the desired shape and size (Adetunji and Salawu, 2008).
The use of vegetable extracts as milk coagulants in soft cheese processing has been known since antiquity and milk coagulants of plant origin have over-ridden the use of animal rennet. Animal rennet is limited for religious reasons (Judaism and Islam), diet (vegetarianism) and being genetically engineered food (Germany and Netherlands forbid the use of recombinant calf rennet) (Roseiro et al., 2003). The use of natural organic coagulants is gaining attention and acceptability over chemical coagulants. 
Chemical coagulants such as aluminum and iron salts are connected to the release of metals in treated water which may induce Alzheimer disease and other carcinogenic problems (Miller et al., 1984; McLachlan 1995). Natural anticoagulants are better alternatives that do not pose the health hazards generated by the use of chemical coagulants. Chitosan, a natural non-toxic polyelectrolyte (Divakaran and Pillai, 2001; Bratskaya et al., 2004) is a substitute already in use and recently Moringa oleifera seed cake was reported to yield protein capable of acting as effective coagulant in water and waste water treatments (Broin et al., 2002; Ghebremichael et al., 2005). Other advantages of natural coagulants lie in their effectiveness at removing suspended materials (Ndabigengesere and Narasiah 1998; Folkard and Sutherland 2002; Raghuwanshi et al., 2002), reduction in the generation of sludge (Folkard \& Sutherland 2002; Jahn 1988), hard water softening ability (Muyibi and Evison 1995) and effective cadmium adsorption (Sharma et al., 2006). Despite these advantages, natural coagulants have been found to cause deposition of residual organic seed material in treated water and its interaction with disinfectants such as chlorine form trichloromethane in the treated water (Bhuptawat et al., 2007). Also, residuals may act as substrate for subsequent microbial growth.

Several authors have documented the successful use of plant extracts in coagulation like in the production of cheese from pasteurized milk. Some of these natural coagulants include Calotropis procera (Sodom apple), Carica papaya, Citrus lemon, Garcinia indica, Tamarindus indica, Averrhoa carambola, Averrhoa bilumbi, Phyllanthus distichus, Hibiscus canabinus, Passiflora edulis, Citrus aurantifolia and fermented maize liquor (Sanjay et al., 2008; Omueti and Jaiyeola, 2006; Aworth and
Muller, 1987; Adetunji and Salawu, 2008). The shelf life, protein content, quality and quantity of cheese produced are consequently affected by the type of coagulants used. In reported production of 'Tofu'-soycurd, natural coagulants gave higher yield and better protein content than the ones produced by chemical coagulants. The chemical coagulants used include calcium sulphate, magnesium chloride, glucono- $\delta$-lactone and alum solution (Sanjay et al., 2008; Omueti and Jaiyeola, 2006).

Gram-negative psychotropic bacteria species are indicted for spoilage resulting in undesirable off-flavor, pigment formation or slimy curd in produced cheese (Brocklehurst and Lund, 1985). Also, the growth of yeasts and molds such as Geotrichum species, Penicillum species, Muccor species and Alternaric species have been implicated in the spoilage, change in flavor, texture and appearance of the cottage cheese (Chen and Hotchkiss 1993). Lemon juice was however used by Adetunji et al. (2008) as a substitute for Calotropis procera during cheese production to improve the anti-microbial quality. Several plant coagulants have since been used to produce cheese that are resistant to microbial actions or could suppress the growth of bacteria, molds and yeasts, leading to longer shelf life of the cheese (Adetunji and Salawu, 2008; Adetunji, 2008; Roseiro et al., 2003).

Naturally derived coagulant materials compete against proprietary coagulants (aluminum sulphate, ferric chloride, polyelectrolytes etc) on technical and economic terms: proprietary coagulants are sold in relatively high volumes at relatively low unit cost and the market is highly competitive and conservative, whereas naturally derived coagulants are obtained in low volume and they are expensive.

Literature abounds on coagulants used for cheese production and water treatment but 
the safety of these coagulants in term of toxicity needs to be evaluated. The brine shrimp lethality assay (a simple bench top assay) is considered a useful tool for preliminary toxicity assessment. This paper therefore tries to determine the toxicity of some natural coagulants of plant origin and chemical coagulants using brine shrimp lethality assay as a test.

\section{MATERIALS AND METHODS}

\section{Collection of coagulants}

Plant materials that constitute natural coagulants were collected from the Faculty of Science area of the University of Ilorin, Ilorin, Nigeria. The plant samples were identified and authenticated at the herbarium of the Plant Biology department, University of Ilorin. The leaf parts of Calotropis procera, Carica papaya and Terminalia cattapa were used. The extracted juice of Citrus limon (Lemon) and Citrus aurantifolia (Lime) were also used. The Citrus limon (Lemon) and Citrus aurantifolia used in this study were harvested from the backyard garden of a private residence at Tanke area, Ilorin. The calcium sulphate and magnesium chloride used in preparing the stock solutions of the chemical coagulants were obtained from $\mathrm{BDH}$ Chemicals Ltd, Poole, England. Solution of a standard anticancer drug, cyclophosphamide (Pfizer) purchased from a registered pharmacy store in Ilorin, Nigeria was included in the assay.

\section{Plant/Fruit extraction and preparation of solution}

The leaves of Calotropis procera, Carica papaya and Terminalia cattapa were cut into pieces and extracted fresh. The leaves samples were soaked in hot distilled water maintained at $80{ }^{\circ} \mathrm{C}$ over a water bath for about five minutes, after which the solution was filtered. Separate fresh plant leaf samples were extracted successively in cold hexane and methanol. The extracts and fractions (i.e. hexane and methanol fractions) were concentrated under pressure to obtain the crude extracts and fractions, which were then dissolved in distilled water and dimethyl sulphoxide (DMSO). The juices of the citrus fruits were obtained by removing the pericarp and squeezing the fruits to obtain the juice which was then filtered. Appropriate weight of the $\mathrm{MgCl}_{2}$ and $\mathrm{CaSO}_{4}$ and distilled water were used to prepare the stock solutions and desired concentrations of the coagulants were prepared from this by serial dilution. $10 \mu \mathrm{g} / \mathrm{ml}$ of cyclophosphamide (Pfizer) was used as standard in the assay.

\section{Brine shrimp lethality assay}

Artemia salina cysts were purchased from Felimar Aquaculture Centre, Ijebu-Ode, Ogun State, Nigeria (produced by Coppens International BV, Helmond, Holland) and the modified method of Krishnaraju et al. (2005) was employed in the assay. The cysts were activated in an improvised hatchery made of plastic dish filled with natural sea water collected from Bar Beach, Lagos, Nigeria. Artemia salina nauplii ( $<48 \mathrm{~h}$ old) were exposed to sample solutions for $24 \mathrm{~h}$ and frequencies of immobility of the 10 nauplii in $5 \mathrm{ml}$ solutions were scored.

The stock solution was prepared by dissolving $0.02 \mathrm{~g}$ extract or salt in $2 \mathrm{ml}$ dimethyl sulphoxide (DMSO) and $1.8 \mathrm{ml}$ of the brine solution was added to $0.2 \mathrm{ml}$ of the stock to give $1000 \mu \mathrm{g} / \mathrm{ml}$ (ppm) solution. Subsequent concentration of 100 and 10 $\mu \mathrm{g} / \mathrm{ml}$ were obtained from this by dilution. Pure undiluted lemon and lime juices were taken for a concentration of 1000 ppm and serial dilutions were done to get solutions of lower concentration for the assay. 10 nauplii were drawn through glass capillary tubes and placed in test tubes containing $4.0 \mathrm{ml}$ of brine solution and $0.5 \mathrm{ml}$ of plant extract solutions or salt solutions of different concentrations 
and made up to $5 \mathrm{ml}$ with brine solution. Negative and positive controls containing 10 nauplii each in test tubes with $5 \mathrm{ml}$ of brine solution mixed with 2 drops of DMSO and 10 $\mu \mathrm{g} / \mathrm{ml}$ of cyclophosphamide were respectively set along side. All assays were carried out in triplicate. The experiments were maintained at room temperature for $24 \mathrm{~h}$ in the laboratory.

\section{Statistical analysis}

The percentage lethality was calculated from the mean of larvae that survived in the extracts and negative control using the arithmetic graphic method of Reish and Oshida (1986). Finney's Probit analysis was used to determine the $\mathrm{LC}_{50}$ of each sample. The percentage mortality was calculated as number of immobile nauplii divided by initial number of nauplii (10) multiplied by 100 . Toxicity of the extract against nauplii was determined by a statistically significant decrease in the survival of nauplii exposed to the samples relative to survival of shrimps in the negative control.

\section{RESULTS AND DISCUSSION}

The activities of the extracts do not follow the order of polarity of solvent of extraction or any particular order; but generally, toxicity reduces as the concentration of the extract reduces. The aqueous extracts of Calotropics procera and Terminalia cattapa are the most toxic of the extracts obtained from the plants with $\mathrm{LC}_{50}$ of 4.37 and $0.1 \mu \mathrm{g} / \mathrm{ml}$ after $24 \mathrm{~h}$ respectively (Table 1). These values fall within the values of compounds with cytotoxic and antitumor properties as proposed by Krishnaraju et al., (2005). Interestingly, aqueous extract of Carica papaya aqueous extract has the highest $\mathrm{LC}_{50}$ value $196.49 \mu \mathrm{g} / \mathrm{ml}$ implying that it is the least toxic of all the plant coagulant extracts, though it has been widely reported for antimicrobial properties (Pawar and Pal, 2002; Kermanshai et al., 2003). The organic solvent extracts of $C$. papaya showed toxic activities against the Artemia salina nauplii which implied that organic solvents are better extractants than water of $C$. papaya though both aqueous and organic solvent extracts were active antimicrobials (Pawar and Pal, 2002). The $\mathrm{LC}_{50}$ of the methanolic extracts of the three (3) leaves coagulants were very close: between 29.48 and $35.50 \mu \mathrm{g} / \mathrm{ml}$, while that of the hexane extracts fell between 27.73 and $42.99 \mu \mathrm{g} / \mathrm{ml}$. The pictorial behaviour of the extractants on the mortality of the nauplii is shown in Figure 1.

The $\mathrm{LC}_{50}$ of aqueous extract of Terminalia cattapa was the lowest of all the extracts and this indicates high toxicity. This very low value calls for caution in the use of this coagulant but may indicate the presence of antitumor and insecticidal compounds. This result depicts the general trend among plants of the genus Terminalia, which are known to contain cytotoxic compounds such as hydrolysable tannins (Mbwanbo et al., 2007). In Tanzania, one of the popular uses of Terminalia species is in the treatment of diarrhea, particularly in HIV patients (Moshi and Mbwambo, 2005; Moshi et al., 2006). The aqueous extract of the leaves are used by traditional healers to treat diarrhea, stomach ache, gastric ulcer, colic, and heartburn (Frhquist et al., 2002). Inclusion of the extracts of this plant leaves in soft cheese production may promote the cure of any of these diseases in the consumer of the finished cheese products but care must be taken to use the extract at low concentration. Aqueous extract of $C$. procera was next in toxicity with $\mathrm{LC}_{50}$ of $4.37 \mu \mathrm{g} / \mathrm{ml}$. Incidentally, the aqueous extract of this plant is the most widely used coagulant in the production of soft cheese particularly in Nigeria. The lower $\mathrm{LC}_{50}$ of the aqueous extract when compared with hexane and methanol extracts may indicate the efficiency of water extraction of the active constituents. Aqueous extraction method is 
the popular extraction method employed by the native cheese producers. However, this low $\mathrm{LC}_{50}$ value calls for caution and dilute solution utilization in the production of cheese. A graphical expression (Figures 1 and 2 ) of these three plant extracts showed $C$. papaya as having the least brine shrimps toxicity while $T$. cattapa has the highest. At $1000 \mathrm{ppm}$ all the plant extracts had almost equally high toxicity (96.67 - 100\% mortality). The mortality of $C$. papaya fell drastically when the concentration was reduced, $16.67 \%$ for $100 \mathrm{ppm}$ and $0.00 \%$ for $10 \mathrm{ppm}$. In the cases of $C$. procera and $T$. cattapa the mortality was still high between 93.33 and $60 \%$ at 100 and $10 \mathrm{ppm}$ respectively.

Calcium sulphate $\left(\mathrm{CaSO}_{4}\right)$, a chemical coagulant used mainly in water treatment plants displayed high toxicity $(7.64 \mu \mathrm{g} / \mathrm{ml})$, while magnesium chloride $\left(\mathrm{MgCl}_{2}\right)$, the second chemical coagulant considered in this study displayed very low toxicity with very high $\mathrm{LC}_{50}$ value. Lemon and lime juices which both have inherent flavors, and are reputed for high antimicrobial properties displayed medium toxicity. The effects of aqueous extracts of Calotropis procera and Terminalia cattapa on the brine shrimps are similar, i.e. high toxicity. The methanol and hexane extracts of Calotropis procera, Carica papaya, Terminalia cattapa, lemon and lime juices and $\mathrm{CaSO}_{4}$ solution are similar in toxicity to the brine shrimps. Aqueous extracts of Carica papaya and $\mathrm{MgCl}_{2}$ have low toxicity effects on the shrimps when compared with the effects of others.

A comparison of the aqueous extracts of all the coagulants in Figure 3 showed that $\mathrm{MgCl}_{2}$ has the least toxicity at all concentrations while $T$. cattapa is the most toxic at all concentrations.

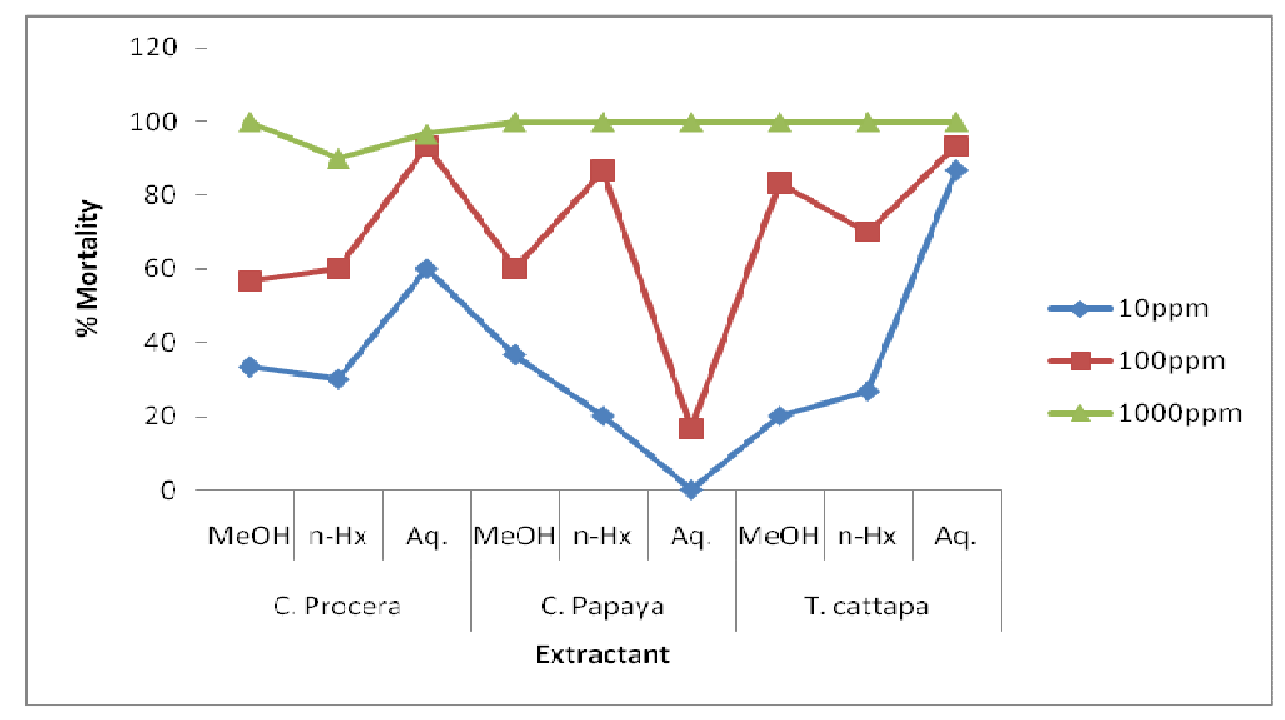

Figure 1: Impact of the extractant on the mortality of Artemia salina. 


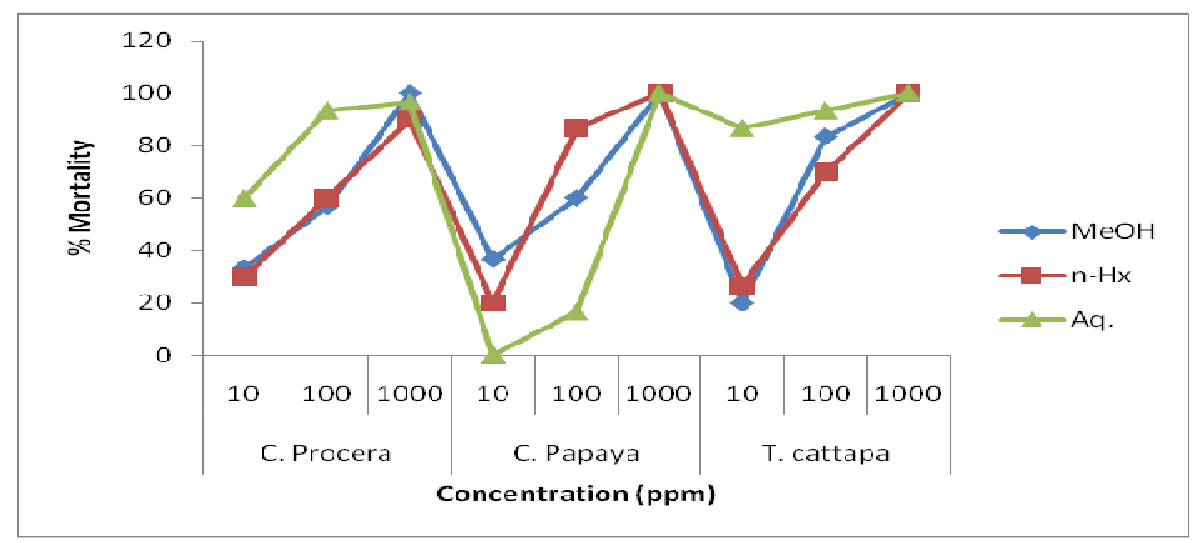

Figure 2: Effect of the plant extract concentration on the mortality of Artemia salina.

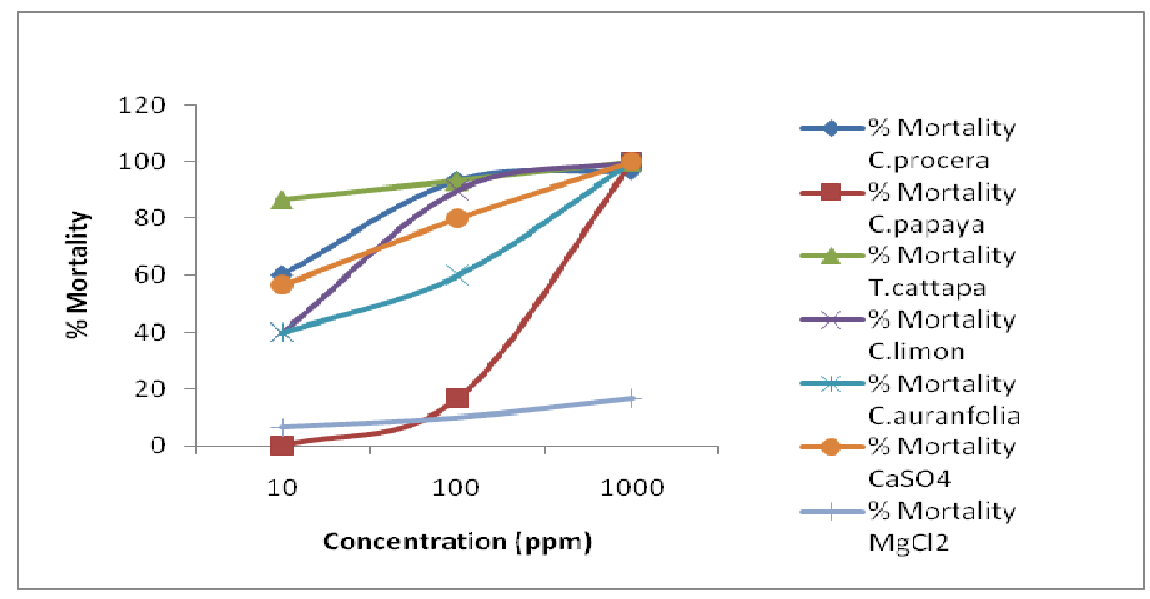

Figure 3: Effect of aqueous extracts of the coagulants on Artemia salina mortality.

C. arantifolia and $\mathrm{CaSO}_{4}$ have medium toxicity at 10 and $100 \mathrm{ppm}$ but they became high at $1000 \mathrm{ppm}$. The choice of coagulants is determined by the objective and aim of application. All the coagulants are safe to Artemia salina nauplii at concentrations lower than $1000 \mathrm{ppm}$. Therefore both natural and chemical coagulants can always find their appropriate usage based on economy and purpose.

Lemon and lime juices both resulted in the same mortality value (40\%) at $10 \mathrm{ppm}$ and $100 \%$ at $1000 \mathrm{ppm}$ but at a concentration of
$100 \mathrm{ppm}$ the lemon juice had a higher toxicity (90\% mortality) than lime juice $(60 \%$ mortality). Lemon juice therefore had a lower $\mathrm{LC}_{50}(14.47 \mu \mathrm{g} / \mathrm{ml})$ than lime juice $(26.09$ $\mu \mathrm{g} / \mathrm{ml}$ ) thereby implying that lemon juice is more toxic than lime juice. The standard antitumor drug used, cyclophosphamide had $96.67 \%$ mortality at $10 \mathrm{ppm}$, which is comparable to that of Terminalia cattapa aqueous extract. All our extracts displayed activities at all the concentrations except the aqueous extract of C. papaya that had $0.0 \%$ mortality at $10 \mathrm{ppm}$. 
G.V. AWOLOLA et al. / Int. J. Biol. Chem. Sci. 4(3): 633-641, 2010

Table 1: Brine shrimps toxicity of extracts of natural and chemical coagulants.

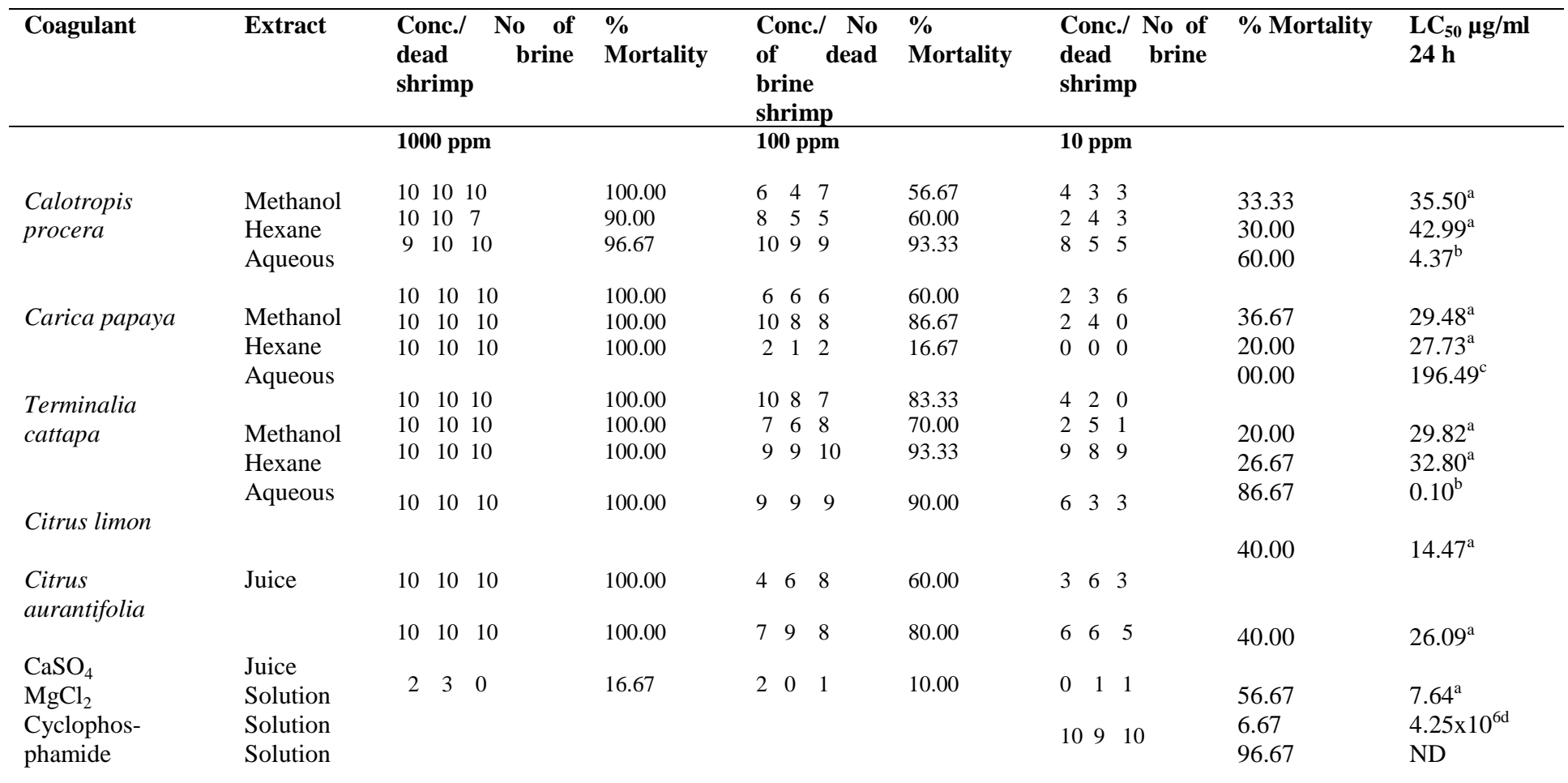

$\mathrm{ND}=\mathrm{Not}$ determined. $\mathrm{LC}_{50}$ values followed by the same letter are not significantly different at $5 \%$ level of significant from one another. 


\section{Conclusion}

Effectiveness and cost of coagulation depend on the coagulant type and concentration. In the selection of a coagulant, the above factors i.e. cost and effectiveness must be considered to achieve the desired objective. This study has shown that these coagulants are toxic to brine shrimps at high concentrations and by implication may be toxic to man also at these high concentrations. Other toxicity tests are suggested to be carried out on these coagulants, particularly those with high toxicity, and safe application concentration can then be determined; from this a possible legislation can be promulgated and communicated as appropriate.

\section{REFERENCES}

Adetunji VO, Alonge DO, Singh RK, Chen J. 2008. Production of wara, a West African soft cheese using lemon juice as a coagulant. Food Science and Technology, 41(2): 331-336.

Adetunji VO, Salawu OT. 2008. West African soft cheese 'wara' processed with Calotropis procera and Carica papaya: A comparative assessment of nutritional values. African journal of Biotechnology, 7(18): 3360-3362.

Adetunji VO. 2008. Comparative assessment of the effect of crude extracts of Carica papaya and Terminalia cattapa, and a bacteriocin on vacuum-packed West African soft cheese ('wara'). African Journal of Microbiology Research, 2: 272-276.

Aworth OC, Muller HG. 1987. Cheesemaking properties of vegetable rennet from Sodom apple (Calotropis procera). Food Chem. 26: 71-79.

Bhuptawat H, Folkard GK, Chaudhari S. 2007. Innovative physic-chemical treatment of wastewater incorporating Moringa oleifera seed coagulant. $J$. Hazardous Materials, 142: 477-482.

Bratskaya S, Schwarz S, Chervonetsky D. 2004. Comparative study of humic acids flocculation with chitosan hydrochloride and chitosan glutamate. Water Res., 38: 2955-2961.

Brocklehurst F, Lund BM. 1985. Microbial changes in cottage cheese varieties during storage at $7^{\circ} \mathrm{C}$. Food Microbiol., 2: 207233.

Broin M, Santaella C, Cuine S, Kokou K, Peltier G, Joel T. 2002. Flocculant activity of a recombinant protein from Moringa oleifera Lam. seeds. Appl. Microbiol. Biol., 60: 114-119.

Chen JH, Hotchkiss JH. 1993. Growth of Listeria monocytogenes and Clostridium sporogenes in cottage cheese in modified atmosphere packaging. J. Dairy Sci., 76: 972-977.

Divakaran R, Pillai VNS. 2001. Flocculation of kaolinite suspensions in water by chitosan. Water Res., 35(16): 3904-3908.

Frhquist P, Mwasumbi L, Haeggstrom CA, Vuorela H, Hiltunen R, Vuorela P. 2002. Ethnobotanical and antimicrobial investigation on some species of Terminalia and Combretum (Combretaceae) growing in Tanzania. $J$. Ethnopharmacol., 79(2): 169-177.

Folkard GK, Sutherland JP. 2002. Development of naturally derived coagulant for water and wastewater treatment. Water Sci. Technol.: Water Supply, 2(5/6): 89-94.

Kermanshai R, McCarry BE, Rosenfeld J, Summer PS, Weretilnyk EA, Sorger GJ. 2003. Benzyl isothiocyanate is the chief or sole anthelminthic in papaya seed extracts. Phytochem., 57: 427-435.

Ghebremicheal KA, Gunaratna KR, Henriksson H, Brummer H, Dalhammar G. 2005. A simple purification and activity assay of the coagulant protein from Moringa oleifera seed. Water Res., 39: 2338-2344.

Jahn SAA. 1988. Using Moringa seeds as coagulants in developing countries. $J$. Am. Water Works Ass., 80: 43-50.

Krishnaraju AV, Rao-Tayi VN, Sundararaju D, Vanisree M, Tsay HS, Subbaraju GV. 2005. Assessment of bioactivity of Indian 
medicinal plants using brine shrimp (Artemia salina) lethality assay. Int. J. Appl. Sci. and Eng., 3(2): 125-134.

Mbwambo ZH, Moshi MJ, Masimba PJ, Kapingu M, Nondo RSO. 2007. Antimicrobial activity and brine shrimp toxicity extract of Terminalia brownie root and stem. BMC Complementary and Alternative Medicine, 7: 9.

McLachlan DRC. 1995. Aluminum and the risk for Alzheimer's disease. Environmetrics, 6: 233.

Miller RG, Kopfler FC, Kelty KC, Strober JA, Ulmer NS. 1984. The occurrence of aluminum in drinking water. J. Am. Water Work Assoc., 76(1): 84-91.

Moshi MJ, Mbwambo ZH. 2005. Some pharmacological properties of extract of Terminalia sericea roots. J. Ethnopharmacol., 97: 43-47.

Moshi MJ, Mbwambo ZH, Kapingu MC, Mhozya VH, Marwa C. 2006. Antimicrobial and brine shrimp lethality of extracts of Terminalia mollis Laws. African J. Trad. CAM., 3(3): 59-69.

Muyibi SA, Evison LM. 1995. Moringa oleifera seed for softening hard water. Water Res., 29: 1099-1105.

Ndabigengesere A, Narasiah KS. 1998. Use of Moringa oleifera seed as a primary coagulant in wastewater treatment. Environ. Technol., 19: 789-800.

Omueti O, Jaiyeola O. 2006. Effects of chemical and plant based coagulants on yield and some quality attributes of tofu.
Nutrition and Food Science, 36(3): 169176.

Pawar SP, Pal SC. 2002. Antimicrobial activity of extracts of Terminalia cattapa root. Indian J. Medical Sci., 56(6): 276278.

Raghuwansi PK, Mandloi M, Sharma AJ, Malviya HS, Chaudhari S. 2002. Improving filterate quality using agrobased materials as coagulant-aid. Water Quality Res. J. Canada, 37: 745-756.

Reish DJ, Oshida PS. 1986. Manual of methods in aquatic environment research Part 10: short-term static bioassays FAO Fisheries Technical Paper 247.

Roseiro LB, Babosa M, Ames JM, Wilbey RA. 2003. Cheese making with vegetable coagulants-the use of Cynara $L$ for the production of ovine milk cheeses. Int. J. Dairy Technol., 56(2): 76-85.

Sanjay KR, Subramanian R, Sethil A, Vijayalakshmi G. 2008. Use of natural coagulants of plant origin in production of soycurd (Tofu). International Journal of Food Engineering, 4(1): 8.

Sharma P, Kamari P, Srivastava MM, Srivastava S. 2006. Removal of cadmium from aqueous system by shelled Moringa oleifera Lam. Seed powder. Biores. Technol., 97: 299-305. 